\title{
Phytochemical and Biological Studies of Senecio glaucus subsp. coronopifolius
}

\author{
Abou El-Hamd H. Mohamed, Dina A. El-Amir, Usama A. A. Radwan, Magdi A. El-Sayed
}

\section{ABSTRACT}

Compositae family is not just an extensive family, but, as expected, a different family. Senecio genus is the biggest genus in the family. In the present study, a phytochemical screening of main secondary metabolites present in $S$. glaucus extracts has been done. In addition to, the antimicrobial, antioxidant and reducing power activity have been measured.

Keywords: Antimicrobial, antioxidant, phytochemical screening, Reducing power, Senecio glaucus.

\section{INTRODUCTION}

Plants are serving the human beings in number of ways, therefore they are considered as gift from the nature for them. Their uses as medicine have been discussed from a long time. These plants based natural chemicals can be extracted from different parts of the plant, which reveals that every part of the plant contains these biologically active compounds (Tiwari et al., 2011). The medicinal plants got considerable importance according their antibacterial, antimalarial, antipyretic, anti-inflammatory, antiviral, anticancer, and antifungal activities (Piero et al., 2011). Senecio glaucus subsp. coronopifolius [Asteraceae] is significantly distributed and have been used in folk medicine for the treatment of different ailments particularly treatment of cancer, cough suppressant, eczema inflammation, and muscular pain. The Plant has been checked for its secondary metabolites; alkaloids (Singh et al., 2017); sesquiterpenoids, monoterpenoids (Bohlmann et al., 1985); diterpenoids (Mohamed, 2015); triterpenoids (Torres et al., 1998); essential oils (Yan et al., 2011), and phenolic compounds (Juarez et al., 1995). Asteraceae (Compositae) is an advanced and botanically highly specialized family of primarily herbaceous plants. In many respects, evolution has occurred, and the main development lines are grouped into tribes by related genera (Benson, 1957). The genus Senecio is the biggest genus in the family of the Asteraceae and includes more than 1500 species (Heywood et al., 1977). Our present
Published Online: February 15, 2022

ISSN: $2684-5199$

DOI : 10.24018 /ejbio.2022.3.1.330

\section{A. H. Mohamed*}

Department of Chemistry, Faculty of Science, Aswan University, Egypt.

(e-mail: abouhassan68@yahoo.com) D. A. El-Amir

Department of Botany, Faculty of Science, Aswan University, Egypt. (e-mail: dodoaid37@gmail.com) U. A. A. Radwan

Department of Botany, Faculty of Science, Aswan University, Egypt. (e-mail: radusa2009@yahoo.com) M. A. El-Sayed

Department of Botany, Faculty of Science, Aswan University, Egypt. (e-mail: magradi2000@yahoo.com)

*Corresponding Author study aimed to evaluate the antimicrobial and antioxidant activity and measuring the reducing power of secondary metabolites. In addition to, a phytochemical screening of main secondary metabolites present in S. glaucus extracts.

\section{MAterials AND Methods}

The plant of $S$. glaucus subsp. coronopifolius was collected in the flowering stage, in March 2018 from Aswan University region. Plant was dried in room temperature, powdered using mechanical grinder and used for phytochemical and biological investigation.

\section{A. Extraction Procedure}

Plant materials were macerated with different systems: pure $n$-hexane; $n$-hexane: methylene chloride $(75: 25) ;(1: 1)$; and (25:75) respectively; pure methylene chloride and methylene chloride: methanol (95:5); and (80:20), respectively; and methanol pure $(\mathrm{MeOH})$ for $24 \mathrm{~h}$ two times for each system. The organic layers were filtered, concentrated using Rotary evaporator till dryness, and stored less than $4{ }^{\circ} \mathrm{C}$ for analysis.

\section{B. Phytochemical Qualitative Examination}

Qualitative examinations of different phytochemicals present in aqueous methanolic $80 \%$ with methylene chloride of $S$. glaucus subsp. coronopifolius extract has done using standard methods. Visual inspection of the appearance of 
color or frothiness has been used as indicator of the presence or absence of a particular phytochemical group (Harborne, 1984).

\section{Quantitative of Phenolic and Flavonoid Compounds \\ 1) The Total Content of Flavonoids}

The total content of flavonoids of the plant sample was established by colorimetric method using aluminum chloride (Chong et al., 2002). In brief, (0.5 mL) of sample was transferred to a test tube then $0.3 \mathrm{~mL}$ of $5 \%$ sodium nitrite solution; $0.3 \mathrm{~mL}$ of $10 \%$ aluminum chloride solution were added after five mints of incubation, and the mixture was kept standing for $6 \mathrm{~min}$. Then, $2 \mathrm{~mL}$ of $1 \mathrm{M}$ sodium hydroxide were added. The mixture was allowed to stand for $15 \mathrm{~min}$, and absorbance was measured at $510 \mathrm{~nm}$. From the calibration curve, the content was calculated, and the result was expressed as mg quercetin equivalent per gm dry weight (DW) and fresh weight.

\section{2) Total Content of Phenolic Compounds}

According to the Folin-Ciocalteu method, the total phenolic compounds were fixed spectrophotometrically (Qugh\&Amerine, 1988). $0.5 \mathrm{~mL}$ of the sample extract was transmitted to a test tube, and $1 \mathrm{~mL}$ of $80 \%$ methanol and 0.5 $\mathrm{mL}$ of Folin-Ciocalteu phenol reagent were added. After incubation time of $5 \mathrm{~min}, 1 \mathrm{~mL}$ of $5 \%$ sodium carbonate was added, mixed well and allowed for an hour. The samples were vortexed and absorbance measured at $700 \mathrm{~nm}$. Phenolic content was reported as $\mathrm{mg}$ Gallic acid equivalent per gm dry weight (DW).

\section{Antioxidant Activities}

\section{1) DPPH Radical Scavenging Activity}

The mixture of reaction (total volume, $3 \mathrm{~mL}$ ), consisting of $1 \mathrm{~mL}$ of $0.2 \mathrm{mM}$ DPPH in ethanol, and $0.5 \mathrm{~mL}$ of methanolic extract, was shaking hard (Blois, 1958). After incubation at room temperature for $30 \mathrm{~min}$, the DPPH remaining was checked by measuring absorbance at $517 \mathrm{~nm}$.

\section{2) Total Antioxidant Capacity}

The experiment was done according (Prieto, 1999). The tubes which containing the fraction and the reagent $(0.6 \mathrm{M}$ sulfuric acid, $28 \mathrm{mM}$ sodium phosphate and $4 \mathrm{mM}$ ammonium molybdate) were incubated at $90^{\circ} \mathrm{C}$ for $90 \mathrm{~min}$. The capacity of antioxidant was expressed as ascorbic.

\section{3) Reducing Power Activity}

According the method of (Oyaizu, 1986), the reducing power was measured. Briefly, phosphate buffer $(2.5 \mathrm{~mL}, 0.2$ $\mathrm{M}, \mathrm{pH}$ 6.6) containing different concentrations of the bark fractions were prepared. Then, it was added to $2.5 \mathrm{~mL}$ of $1 \%$ $(\mathrm{w} / \mathrm{w})$ potassium ferricyanide, and mixed. After incubation at $50^{\circ} \mathrm{C}$ for $20 \mathrm{~min}$, the mixtures were mixed with $2.5 \mathrm{~mL}$ of $10 \%(\mathrm{w} / \mathrm{w})$ trichloroacetic acid, followed by centrifugation at $650 \mathrm{~g}$ for $10 \mathrm{~min}$. The supernatant $(2.5 \mathrm{~mL})$ was mixed with $2.5 \mathrm{~mL}$ of dist. water and $0.5 \mathrm{~mL}$ of $0.1 \%$ ferric chloride. The absorbance of solution was measured at $700 \mathrm{~nm}$. Mean values were obtained from triplicate experiments. Ascorbic acid (40 $\mu \mathrm{g} / \mathrm{mL}$ ) served as positive control.

\section{E. Antimicrobial Activity References}

\section{1) Pathogenic Fungal and Bacterial strains}

Strains were obtained from mycology lab of Faculty of
Science, Aswan University. Extracts were tested against bacteria, including Gram negative (Escherichia coli, Klebsiella pneumoniae); Gram positive strains (Staphylococcus aureus, Staphylococcus epidermidis, Klebsiella pneumoniae); Fungi strains (Candida albican, Candida tropicalis, Candida tamata, Candida ciferri).

\section{2) Disc Diffusion Method}

The method of disc diffusion was used for testing the antibacterial effect of extract. The different dried extracts were respectively dissolved in sterile ( $1 n$-Hexane: $1 \mathrm{CH}_{2} \mathrm{Cl}_{2}$ : drop $\mathrm{MeOH}$ ). A suspension of the tested bacteria, $2 \times 106$ $\mathrm{cfu} / \mathrm{mL}$, was spread on the solid media plates. Filter paper discs of $5 \mathrm{~mm}$ in diameter were individually impregnated with 50 micro of the extract and then placed on the previously inoculated agar plates. The petri dishes were allowed at $4{ }^{\circ} \mathrm{C}$ for $2 \mathrm{~h}$ and then incubated at $37^{\circ} \mathrm{C}$ for $24 \mathrm{~h}$. The of inhibition zones diameters were measured and expressed in millimeters gentamycin (was used as a positive control), sterile disc impregnated with solvent is used as negative control and antibacterial tap used as positive control (Dulge\&Gonuz, 2004; Parek\&Chanda, 2007).

\section{F. Statistical analytics}

The tests were done in triplicate and results are given as the mean standard deviation. The data in all tests were analyzed for statistical significance using Student is Tukey's test and differences were considered significant at $\mathrm{p}<0.05$.

\section{Results AND Discussion}

\section{A. Phytochemical Screening}

In the present study, the qualitatively identified phytochemicals of $S$. glaucus subsp. coronopifolius parts have been tabulated in Table I. In the identification process, the extracts showed many types of chemical constituents in different solvents. The results obtained for the quantitative estimation of some secondary metabolites are presented in Table I.

TABLE I: PHYTOCHEMICAL QUALITATIVE SCREENING OF DIFFERENT EXTRACTS OF SENECIO GLAUCUS

\begin{tabular}{cccc}
\hline \hline Phytochemical screening & Methylene Chloride & $\mathrm{MeOH}$ & $\begin{array}{c}\mathrm{MeOH} \\
80 \%\end{array}$ \\
\hline \hline Alkaloids & - & + & ++ \\
Flavonoids & + & + & ++ \\
Phenolics & + & + & ++ \\
Tannins & - & + & ++ \\
Terpenoids & + & +++ & ++ \\
Proteins & - & - & - \\
Saponins & - & - & + \\
\hline \hline
\end{tabular}

a. p: aerial parts; +: Positive; ++: Moderate; +++: Strongly positive; - : Not detected

\section{B. Total Phenolic}

Our results showed significant variations in phenolic content $(\mathrm{P} \leq 0.05)$ in plant between different polarities of solvent. The highest amount of phenolic content in case of methanolic extract $(0.11 \mu \mathrm{g} / \mathrm{g}$ GAE $)$, while other extracts observed equal value $(0.02,0.013,0.03,0.11$ and 0.025 , respectively) (Fig.1).

\section{Total Flavonoid}

Total flavonoid content of plant showed that the highest 
number of flavonoids were noticed in (Hexane: $\left.\mathrm{CH}_{2} \mathrm{Cl}_{2}, 1: 1\right)$ extract $(1.17 \mu \mathrm{g} / \mathrm{g} \mathrm{QE})$ and other extracts were equal $(0.113$, $0.118,0.256$ and 0.187 , respectively), while the fresh Lablab beans showed no flavonoid content (Fig. 1).

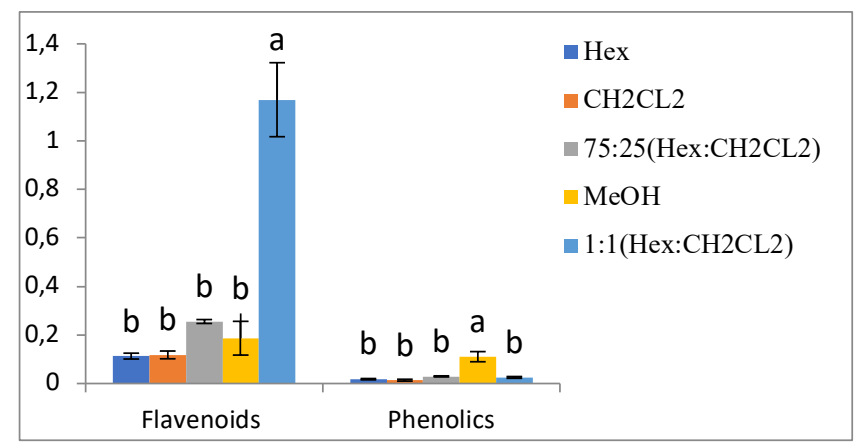

Fig. 1. Total flavonoid and total phenolic of various extracts of Senecio glaucus subsp. coronopifolius. All values are mean $\pm \mathrm{SD}$, Values in the same group with various superscript letters are significantly different, $\mathrm{P}<$ 0.05 (ANOVA after Tukey's test analysis.

\section{Antioxidant Activities}

\section{1) DPPH Scavenging Ability}

The DPPH\% scavenging activity of extracts are presented in (Fig. 2) significant variation $(\mathrm{P}<0.05)$ in the results of the DPPH assay between extract at same concentrations of crude was observed the highest DPPH scavenging activity was in $\mathrm{MeOH}(10 \mu$ gby $69.35 \%)$ and the lowest was at n-Hexane (10 $\mu \mathrm{g}$ by $30.42 \%)$.

\section{2) Total Antioxidant Capacity (TAC)}

Total antioxidant capacity (TAC) of different extracts was varied significantly as function of concentrations $(\mathrm{P}<0.05)$, the TAC increased with increasing the concentration of extract. Hex: $\mathrm{CH}_{2} \mathrm{Cl}_{2}$ (1:1) extract showed higher capacities, it was $0.11 \mu \mathrm{g}$ while the other was $0.05,0.03,0.11$ and 0.12 at $10 \mu \mathrm{g}$ similarly (Fig. 2).

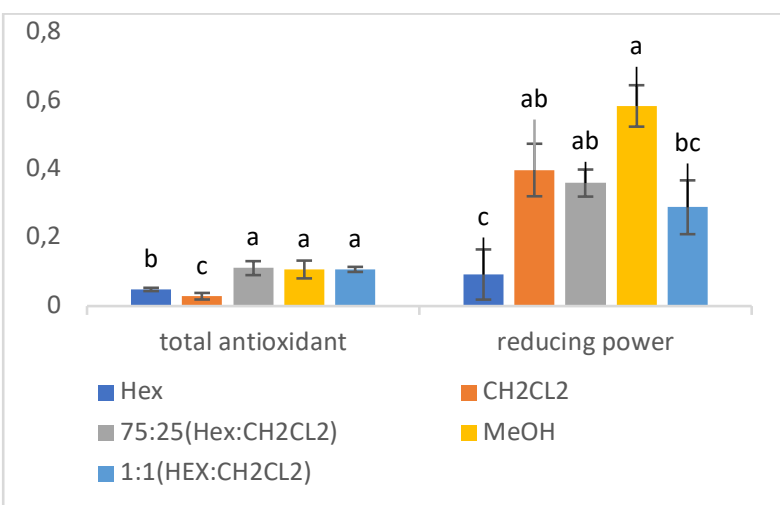

Figure 2. Total antioxidant and reducing power of various extracts of Senecio glaucus subsp. coronopifolius. All values are mean $\pm \mathrm{SD}$, Values in the same group with different superscript letters are significantly different, $\mathrm{P}<0.05$ (ANOVA after Tukey's test analyses.

\section{3) Reducing Power Activity}

The reducing power increased significantly with increasing concentrations, methanolic extract was higher reducing power on the extract effect $58.5 \%$ and other extract show low concentration $(0.01,0.4,0.36$ and 0.29 , respectively (Fig. 2).

\section{E. Antimicrobial Activity}

The general screening result for antibacterial activity are shown different effect on type of Candida species were investigated. The highest activity was demonstrated by pure hexane extract; while the lowest activity was in $\mathrm{MeOH}$ extract (inhibition zone diameter is $0.5 \mathrm{~mm}$ ). The results of present investigation clearly the antibacterial activity vary with the solvent extract of the plants.

TABLE II:ANTIBACTERIAL ACTIVITY SCREENING OF SEVERAL EXTRACTS EXPRESSED AS ABSOLUTE UNIT (AU)

\begin{tabular}{cccc}
\hline \hline Sample & $\begin{array}{c}\text { Candida } \\
\text { albicans }\end{array}$ & Candida auris & $\begin{array}{c}\text { Escherichia coli } \\
\left(\mathrm{G}^{-}\right)\end{array}$ \\
\hline \hline$n$-Hexane & 1.9 & 0.0 & 0.5 \\
$\mathrm{CH}_{2} \mathrm{Cl}_{2}$ & 1.3 & 0.0 & 0.0 \\
$\mathrm{MeOH}$ & 0.0 & 0.9 & 0.0 \\
$n-\mathrm{Hexane}_{2}$ & 0.8 & 0.0 & 0.0 \\
$\mathrm{CH}_{2} \mathrm{Cl}_{2}(1: 1)$ & 0.0 & 0.0 & 0.0 \\
$\mathrm{Control}$ & & & \\
\hline \hline
\end{tabular}

\section{Publication PRinciples}

There is growing interest in using bioactive phytochemicals from natural origin. Phytochemicals obtained from a different part of plants have different effects on human health (Avato\&Argentieri, 2018). The extraction efficiency of biologically active compounds depended on a large number of parameters-extraction method such as type of solvents, temperatures and extraction times (Linchewa, 2017). This result showed that plant have large amount of terpenes, alkaloids, flavonoids, phenolics and tannins in methanol $80 \%$ and methanol pure, while absence of anthraquinones, saponins and proteins. Phenolic compounds are secondary metabolites and synthesized during normal growth and development (Benincasa, 2015), they are more powerful and bioavailable as antioxidant, involved in regulation of ROS, these natural antioxidant compounds have ability for free radicals removing, chelate metal catalysts, and activate antioxidant enzymes (Dravie et al., 2020). Moreover, these compounds help in lower risks of degenerative diseases, especially cardiovascular diseases (Vural et al., 2020).The total content of phenolic compounds for the same species exist in Egypt, also showed comparable values (Mohamed, 2015), while the species growing in Turkey showed that high total phenolic contents that ranged from $11.63 \pm 2.1 \mathrm{mg}$ GAE/g extract in $S$. viscosus to $117.45 \pm 1.8 \mathrm{mg} \mathrm{GAE} / \mathrm{g}$ in $S$. cilicius (Albayrak et al., 2014)].Flavonoids are widespread plant secondary metabolites and act as a natural antioxidant provide protection against oxidative stress (Bhagyawand et al., 2019). It can be exploited for prevention of several chronic diseases by intake of flavonoid rich food (Ginwala et al., 2019). DPPH radical scavenging activity is a measurement of non-enzymatic antioxidant activity. The antioxidant ability of various seeds is closely related to phenolic content and is an important part of the human guard system (Khang et al., 2016). The current results showed that Senecio exhibited higher content of phenolics attained increased level of DPPH radical scavenging activity. The antioxidant activity of Senecio extracts with different type of solvents was studied. The radical scavenging activity of Senecio against DPPH radical was higher and has more protective effects. Moreover, the methanolic root extract of $S$. glaucus growing in Egypt had an antioxidant activity with $\mathrm{IC}_{50}=79.57 \pm 0.74 \mu \mathrm{g} / \mathrm{mL}$ using the DPPH method (Mohamed, 2015). The ferric reducing power activity of Senecio extract was also determined. The reducing capacity 
of a compound may serve as a considerable indicator of its potential antioxidant activity (Lourenco et al., 2019). Major improvement in the reduction power was observed at $10 \mu \mathrm{g}$ for both methylene and methanolic extracts of examined plant. The interest of natural antioxidants from plants has increased because of the safety of these antioxidants in comparison with synthetic antioxidants (Xu et al., 2017). Natural phenolic antioxidants have an essential role in reducing the harmful effects of free radicals (Wang et al., 2010). The correlation between phenolics and scavenging activity was reported previously (Moukette et al., 2015). The antioxidative power of plants can be estimated through their ability to scavenge free radicals. In present study, we showed that $S$. glaucus displayed a potent antioxidant activity through two screening methods.

\section{CONCLUSION}

Our study fixed the secondary compounds; phenolics and flavonoids of $S$. glaucus found in south of Egypt. Our data indicated that $S$. glaucus is a perfect potential source of natural antioxidants, like GA and VA. Our study support researchers in order to fully elucidate the effective constituents of S. glaucus, which leads to the discovery of new and effective drugs.

\section{ACKNOWLEDGMENT}

The authors acknowledge the efforts of all that contributed to the success of this study, especially Dr. Hussein Ali ElDamrany Hussein for his advices and his effort for adjust the manuscript according the journal template.

\section{CONFLICT OF INTEREST}

Authors declare that they do not have any conflict of interest.

\section{REFERENCES}

Albayrak, S., Aksoy, A., Yurtseven, L., \&Yaşar, A. (2014). A comparative study on phenolic components and biological activity of some Senecio species in Turkey. Journal of Pharmacy and Pharmacology, 66(11), 1631-1640.

Avato, P., \& Argentieri, M. (2018). Plant biodiversity: phytochemicals and health. Phytochemistry Reviews, 17(4), 645-656.

Benincasa, P., Galieni, A., Manetta, A. C., Pace, R., Guiducci, M., Pisante, M., \& Stagnari, F. (2015). Phenolic compounds in grains, sprouts and wheatgrass of hulled and non-hulled wheat species. Journal of the Science of Food and Agriculture, 95(9), 1795-1803.

Bhagyawant, S. S., Bhadkaria, A., Narvekar, D. T., \& Srivastava, N. (2019). Multivariate biochemical characterization of rice bean (Vigna umbellata) seeds for nutritional enhancement. Biocatalysis and Agricultural Biotechnology, 20, 101193.

Benson, L. (1957). Plant Classification. Health and Company. Boston. U.S.A.

Blois, M. S. (1958). Antioxidant determinations by the use of a stable free radical. Nature, 181(4617), 1199-1200.

Bohlmann, F., Zdero, C., Jakupovic, J., Misra, L. N., Banerjee, S., Singh, P., \& Robinson, H. (1985). Eremophilane derivatives and other constituents from Senecio species. Phytochemistry, 24(6), 1249-1261.

Chang, C. C., Yang, M. H., Wen, H. M., \& Chern, J. C. (2002). Estimation of total flavonoid content in propolis by two complementary colorimetric methods. Journal of Food and Drug Analysis, 10(3), 178-182.
Dravie, E. E., Kortei, N. K., Essuman, E. K., Tettey, C. O., Boakye, A. A., \& Hunkpe, G. (2020). Antioxidant, phytochemical and physicochemical properties of sesame seed (Sesamum indicum L). Scientific African, 8, e00349.

Dulger, B., \& Gonuz, A. (2004). Antimicrobial activity of some Turkish medicinal plants. Pakistan Journal of Biological Sciences (Pakistan), 7(9), 1559-1562.

Ginwala, R., Bhavsar, R., Chigbu, D. G. I., Jain, P., \& Khan, Z. K. (2019). Potential role of flavonoids in treating chronic inflammatory diseases with a special focus on the anti-inflammatory activity of Apigenin. Antioxidants, 8(2), 35 .

Harborne, J. B. (1984). Methods of plant analysis. Phytochemical methods (pp. 4-6). Springer, Dordrecht.

Heywood, V. H., Harborne, J. B., \& Turner, B. L. (1977). Biology and Chemistry of the Compositae. Academic Press.

Juarez, B. E., Mendiondo, M. E., \& Seeligmann, P. (1995). Flavonoids from leaves and flowers of Liabum polymnioides and L. candidum (Asteraceae). Chemotaxonomical significance. Biochemical Systematics and Ecology, 23(3), 335-6.

Khang, D. T., Dung, T. N., Elzaawely, A. A., \& Xuan, T. D. (2016). Phenolic profiles and antioxidant activity of germinated legumes. Foods, 5(2), 27.

Lincheva, V., Petkova, N., \& Ivanov, I. (2017). Optimization of biologically active substances extraction process from Potentilla reptans L. aerial parts. Journal of Applied Pharmaceutical Science, 7(02), 174-179.

Lourenço, S. C., Moldão-Martins, M., \& Alves, V. D. (2019). Antioxidants of natural plant origins: From sources to food industry applications. Molecules, 24(22), 4132.

Mohamed, S. A. (2015). Phytochemical and biological study of (Senecio glaucus subsp. coronopifolius) (MAIRE) C. ALEXANDER Growing in EGYPT. Az. J. Pharm Sci., 52, 283-298.

Moukette, B. M., Pieme, C. A., Njimou, J. R., Biapa, C. P. N., Marco, B., \& Ngogang, J. Y. (2015). In vitro antioxidant properties, free radicals scavenging activities of extracts and polyphenol composition of a non-timber forest product used as spice: Monodora myristica. Biological Research, 48(1), 1-17.

Ough, C. S., \& Amerine, M. A. (1988). Methods for analysis of musts and wines. New York: John Wiley \& Sons.

Oyaizu, M. (1986). Studies on products of browning reaction antioxidative activities of products of browning reaction prepared from glucosamine. The Japanese journal of nutrition and dietetics, 44(6), 307-315.

Parekh, J., \& Chanda, S. (2007). In vitro antimicrobial activity and phytochemical analysis of some Indian medicinal plants. Turkish Journal of Biology, 31(1), 53-58.

Piero, N. M., Njagi, M. J., Kibiti, M. C., Ngeranwa, J. J. N., Njagi, N. M. E., Njue, M. W., et al. (2012). Herbal management of diabetes mellitus: A rapidly expanding research avenue. Inter. J. of Current Pharmaceutical, Res4(2), 1 - 4.

Prieto, P., Pineda, M., \& Aguilar, M. (1999). Spectrophotometric quantitation of antioxidant capacity through the formation of a phosphomolybdenum complex: specific application to the determination of vitamin E. Analytical biochemistry, 269(2), 337-341.

Singh, D., Sati, S. C., \& Sati, M. D. (2017). In vitro antibacterial and antifungal activity of Senecio chrysanthemoides. World Pharmaceutical research, 6(5), 863-868.

Tiwari, P., Kumar, B., Kaur, M., G. Kaur, G., \&. Kaur, H. (2011). Phytochemical screening and extraction: A review. International Pharmaceutica Sciencia, 1(1), 98-106.

Torres, P., Ayala, J., Grande, C., Macías, M. J., \& Grande, M. (1998). Furanoeremophilanes and a bakkenolide from Senecio auriculavar. major. Phytochemistry, 47(1), 57-61.

Vural, N., Cavuldak, Ö. A., Akay, M. A., \& Anl,, R. E. (2020). Determination of the various extraction solvent effects on polyphenolic profile and antioxidant activities of selected tea samples by chemometric approach. Journal of Food Measurement and Characterization, 14(3), 1286-1305.

Wang, H., Gan, D., Zhang, X., \& Pan, Y. (2010). Antioxidant capacity of the extracts from pulp of Osmanthus fragrans and its components. LWT-Food science and Technology, 43(2), 319-325.

Xu, D. P., Li, Y., Meng, X., Zhou, T., Zhou, Y., Zheng, J., ...\& Li, H. B. (2017). Natural antioxidants in foods and medicinal plants: Extraction, assessment and resources. International journal of molecular sciences, 18(1), 96.

Yan, Y., Lei, Z., Yu Fang, W., Man Li, C., Chang Hong, H., Yu Cheng, G., et al. (2011). Chemical and pharmacological research on plants from the genus Senecio. Chemistry \& Biodiversity, 8(1), 1372 . 